Original Research Paper

\title{
Regeneration of Lyes for Cleaning-In-Place (CIP) Processes in Dairies: Comparison of Recycled Potash and Soda Solutions Cleaning Properties
}

\author{
${ }^{1}$ Marie Furic, ${ }^{1}$ Anne Elain, ${ }^{2}$ Walid Blel and ${ }^{1}$ Olivier Sire \\ ${ }^{1}$ Laboratoire d'Ingénierie Des Matériaux de Bretagne (LIMATB), EA 4250, \\ Université de Bretagne-Sud, Rue de Saint Maudé, 56321 Lorient Cedex, France \\ ${ }^{2}$ Laboratoire De Génie Des Procédés, Environnement, Agroalimentaire (GEPEA), \\ UMR CNRS 6144, 37 Bd de l'Université, BP 406, 44602 Saint-Nazaire, France
}

\author{
Article history \\ Received: 19-02-2015 \\ Revised: 27-05-2015 \\ Accepted: 01-07-2015 \\ Corresponding Author: \\ Marie Furic \\ Laboratoire d'Ingénierie des \\ Matériaux de Bretagne \\ (LIMATB), EA 4250, \\ Université de Bretagne-Sud, \\ Lorient, France \\ Email: marie.furic@univ-ubs.fr
}

\section{Introduction}

The cleaning of production and converting equipment is an essential step in the dairy industry. In fact, the quality of finished products, the health compliance and the performance of the equipment are directly conditioned by the cleaning quality (Gillham et al., 1999). For several years, the use of automated stations of Cleaning-In-Place (CIP) has permitted a better control of the cleaning step with a consequent reduction of plant downtime, energy and quantity of washing products. However, these operations lead to an excessive consumption of water and chemicals. In dairies, caustic soda consumption reaches almost $120 \mathrm{t}$ per year for a plant producing $10^{6} \mathrm{~L}$ of milk a day whereas the entire cleaning procedure (water flushing, cleaning/disinfection and rinsing cycles) represents up to $90 \%$ of the volume discharged to sewage treatment

\begin{abstract}
The regeneration of lyes for their integration in the dairy CIP was investigated applying an original process combining adsorption/coagulation and flocculation operations. Solutions of hydroxide $(\mathrm{KOH})$ and caustic soda $(\mathrm{NaOH})$ soiled with $1 \%$ $(\mathrm{v} / \mathrm{v})$ of whole milk were submitted up to twenty successive regeneration The multiple recycling of the regenerated solutions was found to turbidity, total Chemical Oxygen Demand (COD) and Total Nitrogen (TN) content simultaneously with a decrease of surface tension $(\gamma)$ and equilibrium contact angle $\left(\theta_{\mathrm{e}}\right)$. Along regeneration cycles, potash solutions exhibit quite a distinct trend from soda, especially a lower TN increase and a faster reduction of $\gamma$ leading to a significant lower value of the critical micelle concentration $\left(32 V s .36 \mathrm{mN} . \mathrm{m}^{-1}\right)$. These alterations can be correlated with the accumulation of surfactant molecules in the cleaning solutions derived from the saponification of fatty acids and the degradation of amino acids that can originate an improvement of the
\end{abstract}

Keywords: Dairy Plant, Cleaning-In-Place, Caustic Soda, Potash, Physicochemical Regeneration Process plants (Daufin et al., 2000). Within the actual context of sustainable development and the current EU regulations, dairy manufacturers are urged to significantly reduce their cleaning effluents and sludge particularly through recycling used CIP solutions. Most soils are a combination of organic and inorganic deposits, such as 'milkstone', which is a combination of calcium caseinate and calcium phosphate. Alkaline chemicals are used to remove organic soiling (e.g., proteins such as casein) and inorganic soiling (e.g., magnesium and calcium from hard water). The most common lyes employed in dairy CIP systems are mainly soda-based solutions often including surfactants, soil suspenders, wetting agents, water softeners or other agents. The alkaline cleaning step is typically carried out using a $0.5-2 \%(\mathrm{w} / \mathrm{w})$ caustic soda at a temperature in the range of $70-90^{\circ} \mathrm{C}$ for about 30 45 min (Ricketts, 2008). 
Under those extreme conditions, it is well-established that the main milk components undergo various chemical degradation reactions that yield organic fouling matter and coloring substances. On the other hand, the alkaline hydrolysis of the milk proteins and the saponification of fat both produce natural surfaceactive compounds responsible for lowering the surface tension of the cleaning solution (Condat-Ouillon, 1995; Merin et al., 2002; Alvarez et al., 2007). Depending on the processing practice and soiling load on the process equipment, the cleaning solutions may be either discharged after one use or re-used in other cleaning cycles before being discharged and renewed. The solution replacement delay varies in a large extent regardless the equipment to be cleaned and is generally solely based on qualitative criteria, i.e., color or odor of the lye (Dresch et al., 1999).

Among the potential techniques to eliminate soils particles from caustic cleaning solutions used in dairies, membrane technologies were the most extensively studied. The effectiveness of CIP coupled with microfiltration (Tragardh and Johansson, 1998), ultrafiltration (Dresch, 1998) and nanofiltration (Räsänen et al., 2002; Gésan-Guiziou et al., 2007; Suárez et al., 2012) operations was demonstrated for both ensuring the recovery of $\mathrm{NaOH}$ solutions and reducing the load of industrial solutions discharge. MF was found to retain less surfactants compounds and provide a less expensive technology than UF and NF. However, it results in higher COD concentration in the recycled caustic solution (Gésan-Guiziou et al., 2007). According to some authors (Merin et al., 2002; Alvarez et al., 2007), as recycled cleaning solutions had a lower $\gamma$ compared to newly prepared ones, they had a better cleaning efficiency and provide much faster cleaning rates of the equipment.

Recently, Welschbillig et al. (2014) reported the efficiency of an innovative physicochemical process for the recovery of soiled soda CIP solutions which combines adsorption/coagulation and flocculation sequences and a final separation step by settling or flotation. This treatment was found relevant for removing both soluble and insoluble matters when applied on caustic soda soiled with a whole milk. A mean reduction rate of $50-55 \%$ of the cumulated total COD was recorded along twenty repeated regeneration cycles. In comparison with membrane operations, this physicochemical process is expected to provide significant savings of operating costs, up to about 2.5 fold (80 Vs. $200 \mathrm{k} €$ per year) (Dif, 2013).

Although alkaline washing solutions are most often composed of sodium hydroxide $(\mathrm{NaOH})$, potassium hydroxide $(\mathrm{KOH})$ has a more cleaning power due to its reaction with fats which form soft soaps (Reinish, 1952). However, $\mathrm{KOH}$ is not used so much in CIP because it costs higher than $\mathrm{NaOH}$ (Hargreaves, 2003), but it is a part of the formulation of several commercial detergents (P3-Ultrasil 115 (Ecolab), Cyndan Hi-Surf (Cynda)) used for cleaning sensitive equipment such as filtration membranes. Potash solutions regeneration for multiple reuses could be an alternative which allows compensate for this high cost. The objective of this study is to evaluate the substitution of soda by potash and the integration of potash lyes into dairy cleaning-in-place through a physicochemical regeneration process. Hence, successive physicochemical regeneration assays were conducted on potash solutions to determine the effects of the process on the chemical (COD and TN) and physicochemical (surface tension and wettability) characteristics of regenerated solutions in comparison to those obtained with sodium hydroxide solutions.

\section{Materials and Methods}

Natural sodium bentonite (Na-bentonite Elofloc 2-1 Elodys International, France) was used as the coagulant in suspension form in water at 50 g.L $\mathrm{L}^{-1}$. Flocculation was performed by a cationic polyacrylamide of high molecular weight $\left(\approx 5-610^{6}\right.$ Dalton, EM 949 FLOPAM CT, Floerger SNF) used as a 5 g.L $\mathrm{L}^{-1}$ suspension. Physicochemical regeneration process was conducted as previously described (Dif et al., 2012). In brief, the use of soiled caustic solutions in cleaning cycles was mimicked by the incorporation of whole milk at $1 \%(\mathrm{v} / \mathrm{v})$ to induce a loading charge (COD) equivalent to that encountered in industrial CIP solutions. For the tests, $13.5 \mathrm{~L}$ of an aqueous $0.5 \mathrm{M}$ potash solution were heated to $80^{\circ} \mathrm{C}$. The $1 \%(\mathrm{v} / \mathrm{v})$ whole milk was added and the temperature was maintained at $80^{\circ} \mathrm{C}$ for $15 \mathrm{~min}$. After this contact time, the solution was cooled to $60^{\circ} \mathrm{C}$ and regenerated by successive additions of coagulant and flocculant with stirring at $200 \mathrm{rpm}$ (step 1) at optimal concentrations. The solution was decanted for $30 \mathrm{~min}$ (step 2). Then the flocs collected at the bottom of the decanter were centrifuged at $7500 \mathrm{~g}$ for $10 \mathrm{~min}$ (step 3). The volume and the molar titer of supernatant were adjusted at the end of the separation phase before each new cycle. This protocol was repeated for up to 20 cycles $(n=3)$.

Turbidity of the alkaline CIP solutions was measured with a HACH Nephelometer 2100N (HACH, Colorado, USA). $\mathrm{COD}$ and $\mathrm{TN}$ analyses were performed by micromethods (Nova 60, Merck KGaA, Germany). Surface tension tests were carried-out at room temperature with an automatic BP 100 Tensiometer (KRUSS GmbH, Germany) using a Wilhelmy plate. Contact angles were determined by goniometry (Digidrop, GBX, France) between a sessile drop of regenerated solution and a stainless steel plate.

\section{Results}

The turbidities of $\mathrm{KOH}$ solutions were measured after each physicochemical regeneration (Fig. 1). An increase in turbidity was observed with the successive regenerations. At first, this increment was moderate $(<200$ 
NTU until the ninth regeneration cycle) and, then, it was accelerated from the tenth cycle to reach 1000 NTU at the fifteenth regeneration cycle. The turbidity continues to increase in the subsequent cycles beyond the detection range of the turbidimeter. In the case of regenerated solutions of sodium hydroxide, their turbidities have varied a little and stabilize between 4 and 14 NTU over the twenty successive regenerations.

$\mathrm{COD}$ and $\mathrm{TN}$ of regenerated $\mathrm{KOH}$ solutions were measured and compared to the values obtained in the presence of caustic soda (Dif, 2013). These results were also compared to the values of accumulated COD and $\mathrm{TN}$ induced by the addition of $1 \%(\mathrm{v} / \mathrm{v})$ whole milk at each regeneration cycle. All these results are displayed in Fig. 2. Similar evolutions of COD values were observed for potash and sodium hydroxide regenerated solutions until the sixteenth regeneration (Fig. 2a). The COD values increased with the number of regenerations until 12 g. $\mathrm{L}^{-1}$, due to the accumulation of organic matter induced by the soiling phase of the cleaning solution with the milk. For the last regenerations, higher COD values were observed in the case of soda solutions (17.5 $V s .14$ g. $\mathrm{L}^{-1}$ for $\mathrm{KOH}$ at the twentieth regeneration).

In Fig. 2b, it was observed that soda and potash solutions exhibit similar TN reduction rates until the sixth regeneration. For subsequent cycles, the amount of residual nitrogen continued to increase linearly (36\% per cycle) in the regenerated caustic soda solutions, while it tended to a limit of $350 \mathrm{mgN} \cdot \mathrm{L}^{-1}$ in the case of potash from the tenth twenty regeneration, which is equivalent to a reduction of $80 \%$ for the next regenerations.

In Fig. 3, it can be observed that the surface tension of $\mathrm{KOH}$ regenerated solutions decrease from 73 to 32 $\mathrm{mN} . \mathrm{m}^{-1}$ at the fourth regeneration and then stabilized at this value from the fifth regeneration. In the case of soda solutions, a similar trend was observed. However, the decrease of $\gamma$ was slower and reached a significant higher threshold of $36 \mathrm{mN} \cdot \mathrm{m}^{-1}$.

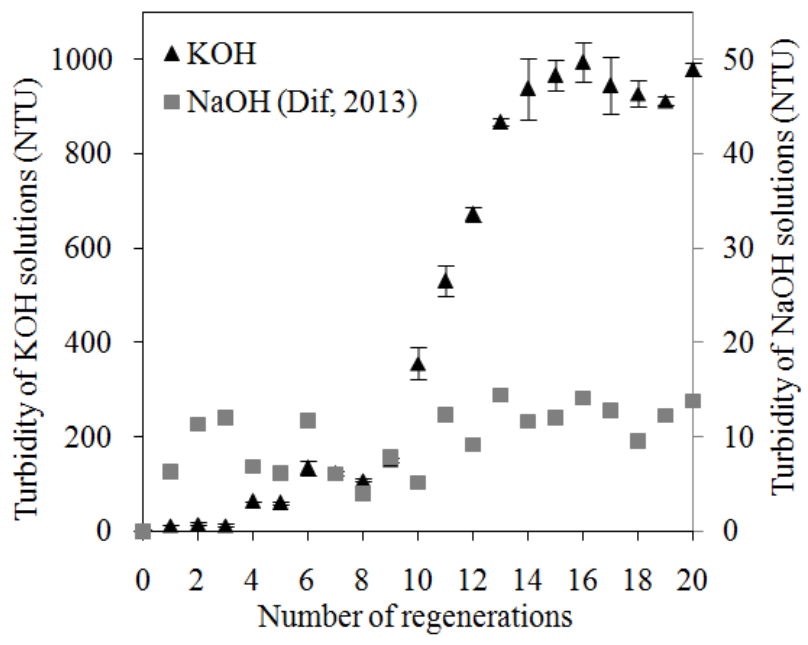

Fig. 1. Turbidity evolution during successive regenerations of alkaline solutions

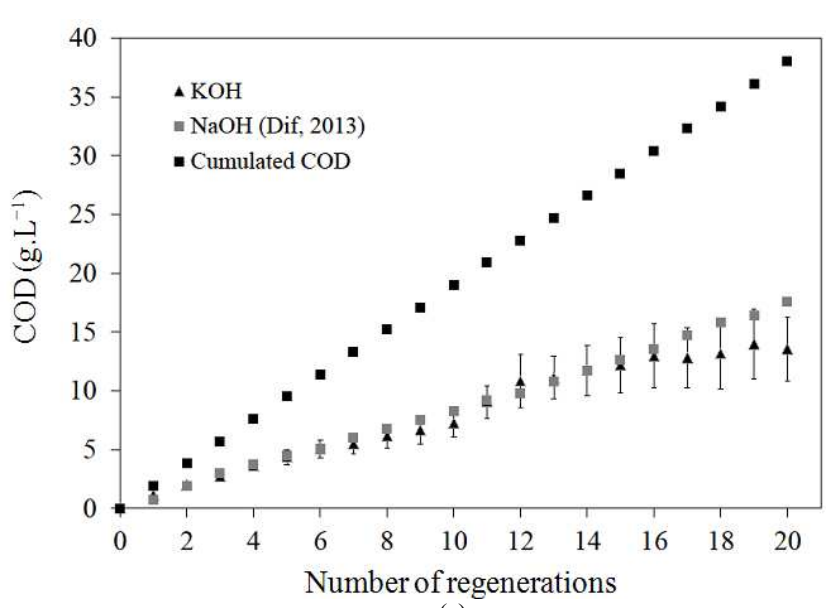

(a)

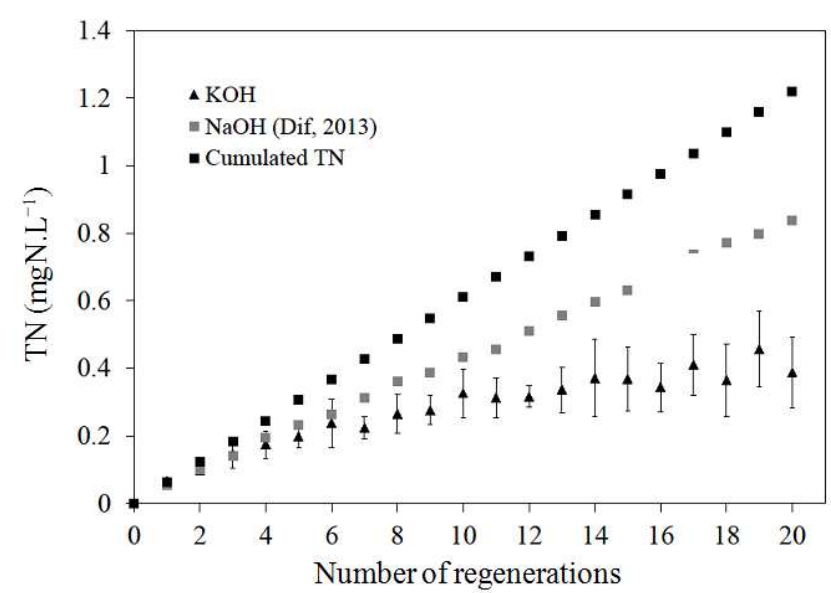

(b)

Fig. 2. Evolution of COD (a) and TN (b) during successive regenerations of alkaline solutions 


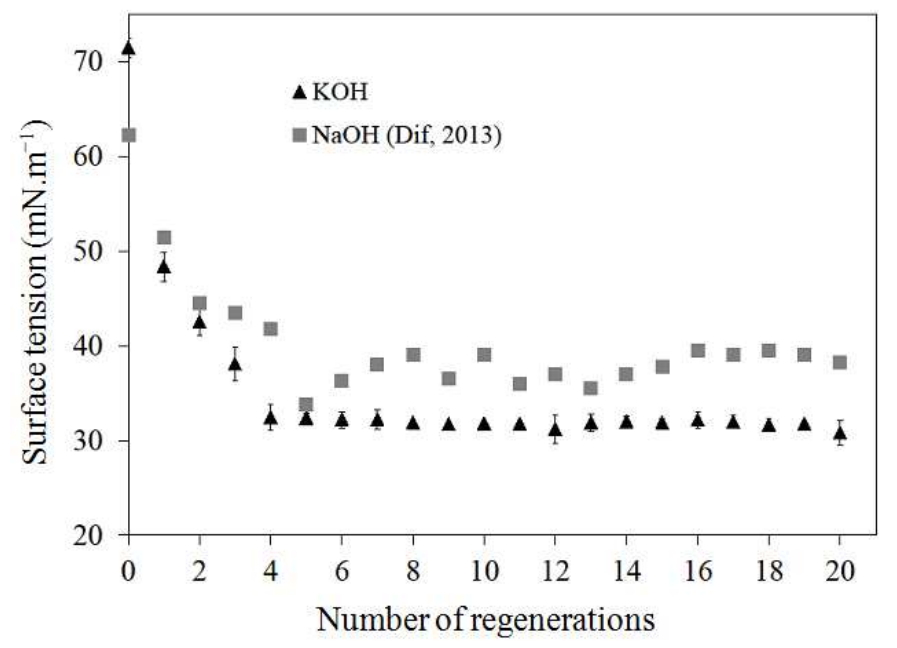

Fig. 3. Evolution of surface tension with the successive regenerations of $\mathrm{NaOH}$ and $\mathrm{KOH}$ solutions

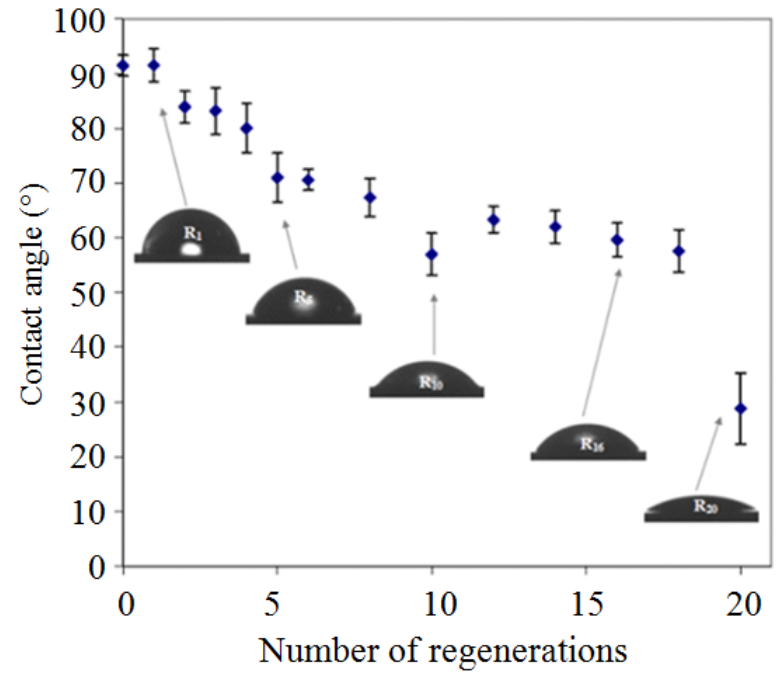

Fig. 4. Evolution of the contact angle between $\mathrm{KOH}$ solutions drop and a stainless steel plate (picture) along successive regenerations

In Fig. 4, the contact angle of regenerated potash solutions was greatly reduced during successive regenerations, indicating an increase in the wetting power of solutions.

\section{Discussion}

The physicochemical regeneration efficiency of $\mathrm{KOH}$ solutions was assessed using turbidity measurements. In comparison with regenerated sodium hydroxide solutions, the turbidity increment of potash solutions was caused by the formation of potassium carboxylates remaining in solution due to their high solubility. Thus, the increase in turbidity during regenerations was due to the accumulation of transformed organic matter.
The COD accumulation obtained by the introduction of $1 \%(\mathrm{v} / \mathrm{v})$ whole milk without regeneration process was performed to estimate the accumulation of organic matters (cumulated COD in Fig. 2a) during the twenty cycles. This parameter allows for the estimation of the reduction rate of the total COD during the successive regenerations. The obtained mean COD reductions were 54 and $56 \%$ for soda and potash, respectively. During successive regenerations of the two alkaline solutions, an increasingly intense brown color was observed. This phenomenon of browning, called "Maillard browning", was caused by a complex set of reactions, involving sugars and amino acids stemming from milk and led to the formation of brown pigments (Condat-Ouillon, 
1995). These pigments were not eliminated by the physicochemical treatment and accumulate in the regenerated solutions giving them this color. The residual COD appeared to be related to the degradation products of lactose. In fact, regeneration tests (data not shown) carried out on soda only soiled by $1 \%(\mathrm{v} / \mathrm{v})$ lactose of a $50 \mathrm{~g} . \mathrm{L}^{-1}$ stock solution showed the presence of the same brown pigments and COD values of these regenerated solutions were decreased by half compared to those contaminated with $1 \%(\mathrm{v} / \mathrm{v})$ milk. The browning phenomenon was also observed after regeneration of dairy CIP solutions using membrane ultrafiltration process (Dresch et al., 2001).

The observed difference of TN reduction, between the two alkaline solutions, could be explained by the effect of their counterions $\left(\mathrm{Na}^{+} / \mathrm{K}^{+}\right)$on the solubilization of milk proteins. According to El Haitami (2010) and Vrbka et al. (2006), the $\mathrm{Na}^{+}$cations have an effect of salting-in of proteins higher than $\mathrm{K}^{+}$cations. Although both cations have the same valence, the hydrated radius of $\mathrm{Na}^{+}$is higher than that of $\mathrm{K}^{+}(1.8 \mathrm{Vs} .1 .3 \AA)$. Thus, the bonds formed by ion pair, between the carboxyl groups of the amino acid (especially aspartic and glutamic acids) and these two counterions, are two times lower with $\mathrm{K}^{+}$cations. During regenerations, the salting-out effect, seen with solutions of potassium hydroxide, is amplified, owing to the accumulation of $\mathrm{K}^{+}$cations introduced for the molar titer correction of the solutions at the end of each regeneration. As a result of the overabundance of $\mathrm{K}^{+}$cations, the amount of the components that need to be solvated will increase and a competition will happen with proteins for the solvation, which will lead to deplete the solvent available for proteins solvation (El Haitami, 2010).

This difference in $\mathrm{TN}$ reduction between $\mathrm{NaOH}$ and $\mathrm{KOH}$ solutions was observed from the sixth regeneration. The same observation should be made for the evolution of the residual COD between the two tested solutions given the composition of the milk protein. However, the obtained results showed a linear evolution of the COD accumulation in the two solutions and could be explained by the accumulation of other organic content in resulting from the formation of tensioactive molecules. As the potassium carboxylates are more soluble than those of sodium, there is a greater accumulation of organic carbon in the regenerated potash solutions.

The observed decrease of $\gamma$ can be attributed to the chemical hydrolysis of the main milk constituents in the alkaline cleaning mainly saponification of lipids into fatty acids and, to a lesser extent, to proteins hydrolysis into peptides and amino acids. These two phenomena lead to the formation of mixed surfactant molecules. These components accumulate in the solutions until a limit concentration called Critical Micelle Concentration (CMC). The formed potassium carboxylates were more soluble than sodium, allowing a faster achievement of this critical value (4th regeneration $V s$. 6th).

The reduction of the contact angle of regenerated potash solutions in comparison to soda ones was correlated with the appearance of surfactants in regenerated solutions. In fact, surfactants disrupt the cohesion of the molecules (as evidenced by the decrease in $\gamma$ ), which allows a better spreading of the liquid on solid surfaces and hence, a better wetting.

\section{Conclusion}

This study was carried out to evaluate the effect of the physicochemical regenerations by adsorptioncoagulation-flocculation on chemical properties (COD, $\mathrm{TN}$ ) and on physicochemical properties (surface tension, contact angle) of potash solutions. Comparison of these parameters to those obtained with soda solutions was performed. For similar conditions of alkalinity and concentration of treatment reagents, the efficiency of the regeneration process of potash solutions was confirmed. It has even been demonstrated that it allows obtaining a better cleaning properties than those of soda. In fact, the formation of potassium carboxylates, which is more soluble than sodium carboxylates, allows increasing the detergency of regenerated potash solutions. Moreover, a higher reduction of nitrogen compounds, due to a higher proteins salting out effect, in the regenerated solutions is observed with potash in comparison to soda. Thus, despite its higher price, the integration of potash, as CIP detergent in substitution of soda is possible thanks to the physicochemical regeneration. The regeneration by physicochemical process reduced the amount of consumed active material and the use of potash as alkaline detergent should increase the efficiency of the cleaning step while reducing its environmental impact. This point will be validated by the comparison of the detergency of the two alkaline solutions for cleaning sensitive equipment, especially the organic filtration membranes.

\section{Acknowledgement}

The authors are greatly indebted to the industrial partner: Eau and Industrie, Pluméliau (France), for its active contribution to this research program and for its financial support.

\section{Author's Contributions}

Marie Furic: Contributed to the literature review and conducted all the experimental studies.

Anne Elain, Walid Blel and Olivier Sire: Participated in the data-analysis and contributed to the drafting and revising of the manuscript. 


\section{Ethics}

This article is original and contains unpublished material. The corresponding author confirms that all of other authors have read and approved the manuscript and no ethical issues involved.

\section{References}

Alvarez, N., G. Gésan-Guiziou and G. Daufin, 2007. The role of surface tension of re-used caustic soda on the cleaning efficiency in dairy plant. Int. Dairy J., 17: 403-411. DOI: 10.1016/j.idairyj.2006.04.008

Condat-Ouillon, C., 1995. Regeneration by tangential filtration of alkaline solutions of NEP in the dairy industry (in French), PhD Thesis, Institut National Plytechnique Toulouse, France.

Daufin, G., G. Gesan-Guiziou and E. Boyaval, 2000. Minimisations des rejets liquides de l'industrie laitière par traitements des effluents à l'aide de procédés à membrane. La Tribune de l'eau, 53: 175183.

Dif, M., 2013. Application of an adsorption-coagulationfloculation regeneration process of acidic and basic solutions for Cleaning in Place systems: Effect of treatment on the physicochemical and cleansing properties of the recycled solutions (in French). PhD Thesis, Université de Bretagne Sud, France.

Dif, M., W. Blel and O. Sire, 2012. New physicochemical regeneration process of CIP solutions. Chemical Eng. Trans., 29: 829-834. DOI: 10.3303/CET1229139

Dresch, M., 1998. Membrane processes for regeneration of cleaning solutions in the dairy industry (in French). PhD Thesis, Ecole Nationale Supérieure Agronomique Rennes, France.

Dresch, M., G. Daufin and B. Chaufer, 1999. Membrane processes for the recovery of dairy cleaning-in-place solutions. Lait, 79: 245-259.

DOI: 10.1051/lait:1999220

Dresch, M., G. Daufin and B. Chaufer, 2001. Integrated membrane regeneration process for dairy cleaningin-place. Sep. Purif. Technol., 22: 181-191.

DOI: 10.1016/S1383-5866(00)00128-3

El Haitami, A.E., 2010. Caractérisation physicochimique de films multicouches de polymères obtenus par interactions électrostatiques et par liaisons covalentes. $\mathrm{PhD}$ Thesis, Université Strasbourg, France.

Gésan-Guiziou, G., N. Alvarez, D. Jacob and G. Daufin, 2007. Cleaning-in-place coupled with membrane regeneration for re-using caustic soda solutions. Sep. Purif. Technol., 54: 329-339.

DOI: 10.1016/j.seppur.2006.10.007
Gillham, C.R., P.J. Fryer, A.P.M. Hasting and D.I. Wilson, 1999. Cleaning-in-place of whey protein fouling deposits: Mechanisms controlling cleaning. Food Bioproducts Process., 77: 127-136. DOI: $10.1205 / 096030899532420$

Hargreaves, T., 2003. Chemical Formulation: An Overview of Surfactant-Based Preparations Used in Everyday Life. 1st Edn., Royal Society of Chemistry, Cambridge, ISBN-10: 0854046356, pp: 180.

Merin, U., G. Gésan-Guiziou, E. Boyaval and G. Daufin, 2002. Cleaning-in-place in the dairy industry: Criteria for reuse of caustic $(\mathrm{NaOH})$ solutions. Lait, 82: 357-366. DOI: 10.1051/lait:2002016

Räsänen, E., M. Nyström, J. Sahlstein, O. Tossavainen, 2002. Purification and regeneration of diluted caustic and acidic washing solutions by membrane filtration. Desalination, 149:185-190. DOI: $10.1016 / \mathrm{S} 0011-9164(02) 00757-9$

Reinish, M.D., 1952. Soaps from fatty acids. J. Am. Oil Chemists Society, 29: 506-510. DOI: $10.1007 /$ BF02632641

Ricketts, N., 2008. Cleaning-in-place: Dairy, food and beverage operations-edited by A.Y. Tamime. Int. J. Dairy Technol., 61: 412-413. DOI: $10.1111 / \mathrm{j} .1471-0307.2008 .00423 . \mathrm{x}$

Suárez, L., M.A. Díez and R. García and F.A. Riera, 2012. Membrane technology for the recovery of detergent compounds: A review. J. Industrial Eng. Chem., 18: 1859-1873. DOI: 10.1016/j.jiec.2012.05.015

Tragardh, G. and D. Johansson, 1998. Purification of alkaline cleaning solutions from the dairy industry using membrane separation technology. Desalination, 119: 21-29. DOI: 10.1016/S00119164(98)00087-3

Vrbka, L., J. Vondrášek, B. Jagoda-Cwiklik, R. Vácha and P. Jungwirth, 2006. Quantification and rationalization of the higher affinity of sodium over potassium to protein surfaces. Proceedings of the National Academy of Sciences, 103: 15440-15444. DOI: 10.1073/pnas.0606959103

Welschbillig, M., W. Blel and M. Dif, 2014. Cleaning solution obtained by recycling a spent solution. Brevet International WO 2014/060658 A1. 